Volume 71, Number 1, Pages 252-272 (2022)

DOI:10.31801/cfsuasmas.744141

ISSN 1303-5991 E-ISSN 2618-6470

Research Article; Received: May 28, 2020; Accepted: August 18, 2021

\title{
MODIFIED-LINDLEY DISTRIBUTION AND ITS APPLICATIONS TO THE REAL DATA
}

\author{
Coşkun KUŞ ${ }^{1}$, Mustafa Ç. KORKMAZ ${ }^{2}$, İsmail KINACI ${ }^{3}$, \\ Kadir KARAKAYA, ${ }^{1}$ and Yunus AKDOĞ ${ }^{1}{ }^{1}$ \\ ${ }^{1}$ Department of Statistics, Selçuk University, Konya, TURKEY \\ ${ }^{2}$ Deparment of Measurement and Evaluation, Artvin Çoruh University, \\ City Campus, Artvin, TURKEY \\ ${ }^{3}$ Department of Actuarial Sciences, Selçuk University, Konya, TURKEY
}

\begin{abstract}
In this paper, a new three-parameter lifetime distribution is proposed by mixing modified Weibull and generalized gamma distributions. The point estimation on the distribution parameters are discussed through several estimators. The interval estimation is also studied with two methods based on asymptotic normality and likelihood ratio. A Monte Carlo simulation study is performed to evaluate the biases and mean square errors behaviors of point estimates for a different sample of size. A simulation study is also conducted to investigate the coverage probabilities of confidence intervals. The distribution modeling analyses are provided based on several real data sets to demonstrate the fitting ability of the introduced distribution.
\end{abstract}

\section{INTRODUCTION}

The Lindley $(\mathrm{L})$ distribution is introduced in 18 with cumulative distribution function (cdf) and probability density function (pdf),

$$
F_{L}(x ; \theta)=1-\frac{\theta+1+\theta x}{\theta+1} e^{-\theta x},
$$

and

$$
f_{L}(x ; \theta)=\frac{\theta^{2}}{1+\theta}(1+x) e^{-\theta x}, x>0
$$

2020 Mathematics Subject Classification. Primary 60E05; Secondary 62E15.

Keywords. Confidence interval, data analysis, lifetime distribution, Lindley distribution, point estimates.

@ coskun@selcuk.edu.tr; mcagatay@artvin.edu.tr; ikinaci@selcuk.edu.tr; kkarakaya@selcuk.edu.tr-Corresponding author; yakdogan@selcuk.edu.tr

(D) 0000-0002-7176-0176; 0000-0003-3302-0705; 0000-0002-0992-4133; 0000-0002-0781-3587; 0000-0003-3520-7493.

(C)2022 Ankara University Communications Faculty of Sciences University of Ankara Series A1 Mathematics and Statistics 
respectively, and $\theta>0$ is a parameter.

$\mathrm{L}$ distribution can be represented as a mixture of two distributions with pdf

$$
f_{L}(x ; \theta)=p f_{E}(x ; \theta)+(1-p) f_{G}(x ; \theta),
$$

where $f_{E}(x ; \theta)=\theta e^{-\theta x}$ and $f_{G}(x ; \theta)=\theta^{2} x e^{-\theta x}$ are the pdfs of exponential and gamma distributions respectively and $p=\frac{\theta}{1+\theta}$ is the mixing proportion of distributions. Since the $\mathrm{L}$ distribution is IFR, it is unsuitable for modelling the data that obeys the non-linear hazard rate structure. 12 introduced the power Lindley (PL) distribution, which generalizes the Lindley distribution with the following pdf

$$
\begin{aligned}
f_{P L}(x ; \alpha, \theta) & =\frac{\alpha \theta^{2}}{\theta+1}\left(1+x^{\alpha}\right) x^{\alpha-1} e^{-\theta x^{\alpha}}, x>0, \alpha, \theta>0, \\
& =p f_{W}(x ; \alpha, \theta)+(1-p) f_{G G}(x ; \alpha, \theta),
\end{aligned}
$$

where $f_{W}(x ; \alpha, \theta)=\alpha \theta x^{\alpha-1} e^{-\theta x^{\alpha}}$ and $f_{G G}(x ; \alpha, \theta)=\alpha \theta^{2} x^{2 \alpha-1} e^{-\theta x^{\alpha}}$ are the pdfs of Weibull and generalized gamma $(\mathrm{GG})$ distributions respectively and $p=\frac{\theta}{1+\theta}$ is the mixing proportion of distributions. 12] investigated properties of the PL distribution with an application and outlined that the PL distribution is a better model than the other $\mathrm{L}$ and exponential based distribution.

Moreover, several generalizations have been proposed in the literature in order to increase the flexibility and usefulness of the L model. Some of them are: generalized Lindley (GL) [32], exponentiated Lindley (EL) [22], discrete Lindley [11], extended Lindley 6], beta Lindley 20, 21], exponentiated power Lindley (EPL) [31], odd log logistic power Lindley 1], odd log-logistic Lindley Poisson [24], odd Burr Lindley 3], binomial discrete Lindley [16], Weibull-Lindley [4 and generalized power Lindley 15] among others.

This paper aims to introduce a new flexible distribution that generalizes the $\mathrm{L}$ and PL distributions with the same structure of (1). Furthermore, we are also motivated to propose a new $\mathrm{L}$ distribution because introduced model has various pdf shapes as well as non-monotone hazard rate function (hrf) shapes unlike L and PL models.

The paper is organized as follows: In Section 2, a new lifetime distribution is proposed and several distributional properties are discussed. Several point estimation methods are discussed for the distribution parameters in Section 3 . In Section 4. the interval estimation is considered with two well-known methods. The Section 5 close the paper with three distribution modeling analyses based on real data.

\section{Modified Lindley Distribution and Some Properties}

A random variable $X$ has a Modified Lindley (MoL) distribution if its pdf is given by

$$
f_{M o L}(x ; \boldsymbol{\Xi})=\frac{\theta^{2}}{\theta+1}\left[(\alpha+\beta x) e^{-\theta x^{\alpha}\left(e^{\beta x}-1\right)+\beta x}+\alpha x^{\alpha}\right] x^{\alpha-1} e^{-\theta x^{\alpha}}, x>0,
$$


where $\alpha, \beta, \theta>0$ are parameters and $\boldsymbol{\Xi}=(\alpha, \beta, \theta)$. Indeed MoL distribution is a mixture of two distribution with the following representation:

$$
f(x ; \boldsymbol{\Xi})=p g_{1}(x ; \alpha, \beta, \theta)+(1-p) g_{2}(x ; \alpha, \theta), x>0, \alpha, \beta, \theta>0,
$$

where $p=\frac{\theta}{\theta+1}$ is the weighting parameter of the distributions, $g_{1}(x ; \alpha, \beta, \theta)$ is the pdf of Modified Weibull (MW) distribution introduced in [17, with the following pdf

$$
g_{1}(x ; \alpha, \beta, \theta)=\theta(\alpha+\beta x) x^{\alpha-1} e^{\beta x-\theta x^{\alpha} \exp (\beta x)}, x>0,
$$

and $g_{2}(x ; \alpha, \theta)$ is the pdf of a GG distribution introduced in 28], with the following pdf

$$
g_{2}(x ; \alpha, \theta)=\alpha \theta^{2} x^{2 \alpha-1} e^{-\theta x^{\alpha}}, x>0 .
$$

From (2), we see that the MoL distribution is a two-component mixture of MW and GG distributions with weighting parameter $p$. We denote the MoL distribution with parameter $\boldsymbol{\Xi}$ by $\operatorname{MoL}(\boldsymbol{\Xi})$.

While $\beta \rightarrow 0$, MoL distribution reduces to the PL distribution. While $\beta \rightarrow 0$ and $\alpha \rightarrow 1$, it is reduced to $\mathrm{L}$ distribution.

The cdf and hrf of the MoL distribution are

$$
F(x ; \boldsymbol{\Xi})=1-\frac{1+\theta x^{\alpha}+\theta e^{-\theta x^{\alpha} e^{\beta x}+\theta x^{\alpha}}}{\theta+1} e^{-\theta x^{\alpha}}, x>0
$$

and

$$
h(x ; \boldsymbol{\Xi})=\frac{\theta^{2} x^{\alpha-1}\left\{(\alpha+\beta x) e^{-\theta x^{\alpha}\left(e^{\beta x}-1\right)+\beta x}+\alpha x^{\alpha}\right\}}{1+\theta x^{\alpha}+\theta e^{-\theta x^{\alpha} e^{\beta x}+\theta x^{\alpha}}}, x>0
$$

respectively. The plots of the pdf and hrf are given in Figure 1 to identify their possible shapes. These figures show that the MoL distribution can be unimodal, bimodal, decreasing and firstly decreasing then unimodal shaped. On the other hand, the hrf of MoL can be both monotone and non-monotone structures.

In distribution theory, stochastic ordering is an essential measure for evaluating the comparative behavior of random variables. It is known that $X<_{l r} Y \Rightarrow X$ $<_{h r} Y \Rightarrow X<_{s t} Y$, see 25. For more information about stochastic ordering with different applications, one can see 27]. Likelihood ratio ordering is shortly defined as follow: $X$ is less than $Y$ in the likelihood ratio order (denoted by $X<_{l r} Y$ ) if $f_{X}(x) / f_{Y}(x)$ increases in $x$ over the union of the supports of $X$ and $Y$.

Theorem 1. If $X \sim \operatorname{MoL}\left(\alpha, \beta, \theta_{1}\right)$ and $Y \sim M o L\left(\alpha, \beta, \theta_{2}\right)$ and $\theta_{1}<\theta_{2}$, then $X$ $<_{l r} Y$.

Proof. See Appendix.

Corollary 1. If $X \sim \operatorname{MoL}\left(\alpha, \beta, \theta_{1}\right)$ and $Y \sim \operatorname{MoL}\left(\alpha, \beta, \theta_{2}\right)$ and $\theta_{1}<\theta_{2}$ then $X$ $<_{h r} Y$ and $X<_{s t} Y$. 
MODIFIED-LINDLEY DISTRIBUTION AND ITS APPLICATIONS TO THE REAL DATA255
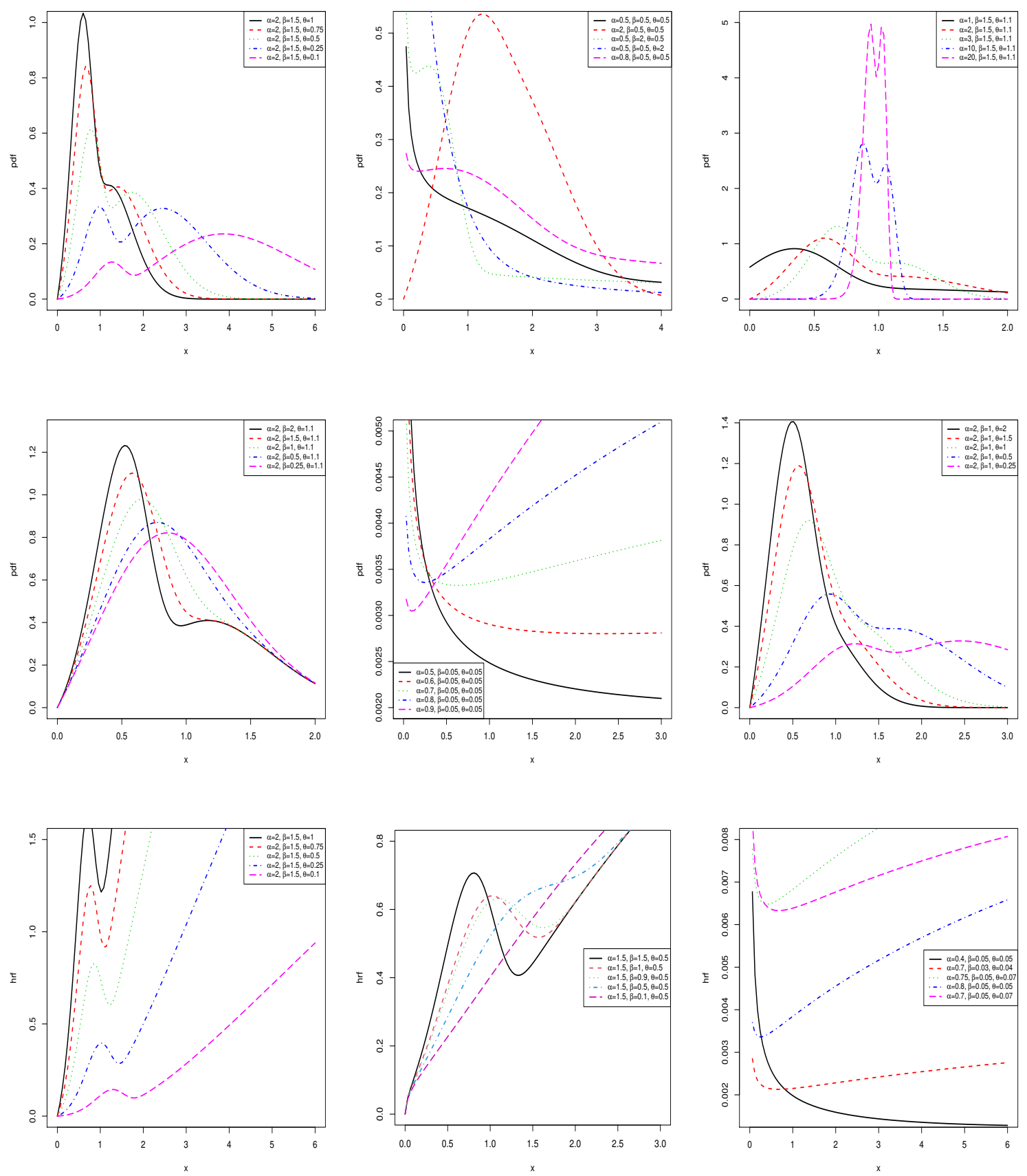

Figure 1. Possible pdf and hrf plots of MoL distribution 
Theorem 2. For $r \in \mathbb{N}^{+}$, the raw moments of $M o L(\boldsymbol{\Xi})$ are given by

$$
\mu_{r}^{\prime}=E\left(X^{r}\right)=\frac{1}{\theta+1}\left[\Gamma(r / \alpha+2) \theta^{-r / \alpha}+\sum_{i_{1}, \ldots, i_{r}=1}^{\infty} A_{i_{1}, \ldots, i_{r}} \Gamma\left(s_{r} / \alpha+1\right) \theta^{1-s_{r} / \alpha}\right] .
$$

Proof. See Appendix.

Corollary 2. The mean and rth central moment of the $M o L(\boldsymbol{\Xi})$ are given, respectively, by

$$
\mu=\frac{1}{\theta+1}\left[\Gamma(1 / \alpha+2) \theta^{-1 / \alpha}+\sum_{i=1}^{\infty} a_{i} \Gamma(i / \alpha+1) \theta^{1-i / \alpha}\right]
$$

and

$$
\mu_{r}=E(X-\mu)^{r}=\sum_{h=0}^{r}(-1)^{h}\left(\begin{array}{l}
r \\
h
\end{array}\right) \mu^{r} \mu_{r-h}^{\prime} .
$$

Using (6), the skewness and kurtosis coefficients can be obtained by

$$
\sqrt{\beta_{1}}=\sqrt{\frac{\mu_{3}^{2}}{\mu_{2}^{3}}} \text { and } \beta_{2}=\frac{\mu_{4}}{\mu_{2}^{2}}
$$

respectively. The mean, variance, skewness and kurtosis are computed for some choices of parameters and given in Table 1. From Table 1, it is seen that the coefficient of kurtosis can take negative and positive values. This shows that the distribution has a flexible structure in data modeling. In addition, it is seen that the new distribution is flatter than the normal distribution. When $\theta$ increases, the kurtosis coefficient increases and the variance decreases. $E(X)$ decreases when the parameter $\beta$ increases.

TABLE 1. The mean, variance, coefficients of skewness and kurtosis for some choices of parameters

\begin{tabular}{llllllllll}
\hline \multicolumn{3}{c}{$\theta=0.9$} & \multicolumn{7}{c}{$\theta=1.5$} \\
\hline$\alpha$ & $\beta$ & $E(X)$ & $\operatorname{Var}(X)$ & Skewness & Kurtosis & $E(X)$ & $\operatorname{Var}(X)$ & Skewness & Kurtosis \\
\hline 0.9 & 0.9 & 1.5597 & 3.0668 & 2.2407 & 9.9440 & 0.7844 & 0.8065 & 2.5707 & 12.4062 \\
& 1.5 & 1.5104 & 3.1444 & 2.2221 & 9.7165 & 0.7466 & 0.8203 & 2.6166 & 12.4272 \\
& 5 & 1.4181 & 3.3299 & 2.1388 & 9.1238 & 0.6687 & 0.7341 & 2.5844 & 11.8172 \\
& & & & & & & & & \\
1.5 & 0.9 & 1.1363 & 0.6088 & 1.1457 & 4.2521 & 0.7436 & 0.2664 & 1.3223 & 5.0558 \\
& 1.5 & 1.0910 & 0.6416 & 1.1738 & 4.1289 & 0.7042 & 0.2750 & 1.4381 & 5.1801 \\
& 5 & 0.9906 & 0.7491 & 1.1068 & 3.6418 & 0.6099 & 0.3188 & 1.5008 & 4.8333 \\
5 & 0.9 & 0.9740 & 0.0536 & -0.1046 & 2.6206 & 0.8486 & 0.0419 & 0.0095 & 2.7336 \\
& 1.5 & 0.9444 & 0.0614 & 0.0376 & 2.3197 & 0.8166 & 0.0466 & 0.2250 & 2.5554 \\
& 5 & 0.8473 & 0.1046 & 0.1864 & 1.5997 & 0.7086 & 0.0764 & 0.5842 & 1.9761 \\
\hline
\end{tabular}




\section{Point Estimation}

In this section, the maximum likelihood, least square, weighted least square, Anderson-Darling, Cramer-von Mises, and maximum product spacing methods are discussed to estimate the MoL distribution parameters. It is noticed that these estimates are also used in [2], [13], 14], 29], [30] among others. Let $X_{1}, X_{2}, \ldots, X_{n}$ be a random sample from the $\operatorname{MoL}(\boldsymbol{\Xi})$ distribution with realizations $x_{1}, x_{2}, \ldots, x_{n}$. Furthermore, $X_{(1)}, X_{(2)}, \ldots, X_{(n)}$ be the corresponding ordered statistics with realizations $x_{(1)}, x_{(2)}, \ldots, x_{(n)}$. Then the log likelihood function can be written by

$$
\begin{aligned}
& \ell(\boldsymbol{\Xi})=2 n \log \theta-n \log (\theta+1)+(\alpha-1) \sum_{i=1}^{n} \log \left(x_{i}\right) \\
& -\sum_{i=1}^{n} \log \left[\left(\alpha+\beta x_{i}\right) \exp \left\{-\theta x_{i}^{\alpha}\left(e^{\beta x_{i}}-1\right)-\beta x_{i}\right\}+\alpha x_{i}^{\alpha}\right] .
\end{aligned}
$$

Hence, the maximum likelihood estimate (MLE) $\widehat{\boldsymbol{\Xi}}$ of $\boldsymbol{\Xi}$ is written by

$$
\widehat{\boldsymbol{\Xi}}=\underset{\Xi}{\arg \max } \ell(\boldsymbol{\Xi}) \text {. }
$$

The maximum product spacing estimate (MPSE) was proposed by 9 . The MPSE $\widehat{\boldsymbol{\Xi}}_{M P S}$ of parameter $\boldsymbol{\Xi}$ are achieved by maximizing

$$
\operatorname{MPS}(\boldsymbol{\Xi})=\frac{1}{n+1} \sum_{i=1}^{n+1} \log \left[F\left(x_{(i)} ; \boldsymbol{\Xi}\right)-F\left(x_{(i-1)} ; \boldsymbol{\Xi}\right)\right],
$$

where, $F$ is MoL cdf given in $(3)$ and $F\left(x_{(0)} ; \boldsymbol{\Xi}\right)=0$ and $F\left(x_{(n+1)} ; \boldsymbol{\Xi}\right)=1$. Note that the MPSE can be written by

$$
\widehat{\boldsymbol{\Xi}}_{M P S}=\underset{\boldsymbol{\Xi}}{\arg \max } \operatorname{MPS}(\boldsymbol{\Xi}) \text {. }
$$

The least square estimate (LSE) $\widehat{\boldsymbol{\Xi}}_{L S E}$ of parameter $\boldsymbol{\Xi}$ are obtained by minimizing the function

$$
L S(\boldsymbol{\Xi})=\sum_{i=1}^{n}\left(F\left(x_{(i)} ; \boldsymbol{\Xi}\right)-\frac{i}{n+1}\right)^{2},
$$

where $F$ is MoL cdf given in (3). Hence, LSE of $\boldsymbol{\Xi}$ is given by

$$
\widehat{\boldsymbol{\Xi}}_{L S E}=\underset{\Xi}{\arg \min } L S(\boldsymbol{\Xi}) \text {. }
$$

The weighted least square estimate (WLSE) $\widehat{\boldsymbol{\Xi}}_{W L S E}$ of $\boldsymbol{\Xi}$ are obtained by minimizing

$$
W L S(\boldsymbol{\Xi})=\sum_{i=1}^{n} \frac{(n+2)(n+1)^{2}}{i(n-i+1)}\left(F\left(x_{(i)} ; \boldsymbol{\Xi}\right)-\frac{i}{n+1}\right)^{2} .
$$


Then the WLSE of $\boldsymbol{\Xi}$ is presented by

$$
\widehat{\Xi}_{W L S E}=\underset{\Xi}{\arg \min } W L S(\boldsymbol{\Xi}) .
$$

The Anderson-Darling (ADE) type estimate $\widehat{\boldsymbol{\Xi}}_{A D}$ of parameters $\boldsymbol{\Xi}$ are obtained by minimizing

$$
A D D(\boldsymbol{\Xi})=-n-\sum_{i=1}^{n} \frac{2 i-1}{n}\left[\log F\left(x_{(i)} ; \boldsymbol{\Xi}\right)+\log \left\{1-F\left(x_{(n+1-i)} ; \boldsymbol{\Xi}\right)\right\}\right] .
$$

The ADE of $\boldsymbol{\Xi}$ is written by

$$
\widehat{\boldsymbol{\Xi}}_{A D}=\underset{\boldsymbol{\Xi}}{\arg \min } A D D(\boldsymbol{\Xi}) .
$$

The Cramer-von Mises (CVME) type estimate, $\widehat{\boldsymbol{\Xi}}_{C V M}$ of parameter $\boldsymbol{\Xi}$ are obtained by minimizing

$$
C V M(\boldsymbol{\Xi})=\frac{1}{12 n}+\sum_{i=1}^{n}\left[F\left(x_{(i)} ; \boldsymbol{\Xi}\right)-\frac{2 i-1}{2 n}\right]^{2} .
$$

The CVME of $\boldsymbol{\Xi}$ is given by

$$
\widehat{\boldsymbol{\Xi}}_{C V M}=\underset{\boldsymbol{\Xi}}{\arg \min } C V M(\boldsymbol{\Xi}) .
$$

In order to achieve the values of estimates, the $R$ functions such as constrOptim, optim or maxLik can be used.

The simulation study is performed for the bias and mean square errors (MSEs) of estimates and the results are presented by graphically. We consider $N=1000$ trials of size $n=20,25, \ldots, 1000$ from the MoL distribution with true parameter $\boldsymbol{\Xi}=(5,5,2)$. All estimates are achieved by using constr0ptim routine in the R. The simulation results are presented in Figs. 2,4. Figs. 2, 4 show that all estimates are consistent since the MSEs decrease to zero for large sample size. The CVME and MPSE have the maximum amount of the biases for all parameters while CVME and WLSE have the maximum MSEs for all parameters. On the other hand, MPSE is the best estimator according to MSEs for small sample size. It is noticed that the MPSE and MLE has almost same MSEs for moderate and large sample size cases. The ADE and LSE have the lowest bias for all parameters. As a final comment on the simulation study, we recommend that the MLE or MPSE should be used to estimate the parameters.

\section{Interval Estimation of MoL Distribution Parameters}

In this section, the confidence intervals (CIs) are discussed for the parameters $a, \beta$ and $\theta$. In general, CIs are constructed by using MLE based on pivotal quantities through the asymptotic normality(AN) property of MLE. These CIs are most 



Figure 2. The empirical means, biases and MSEs of the parameter $\alpha$
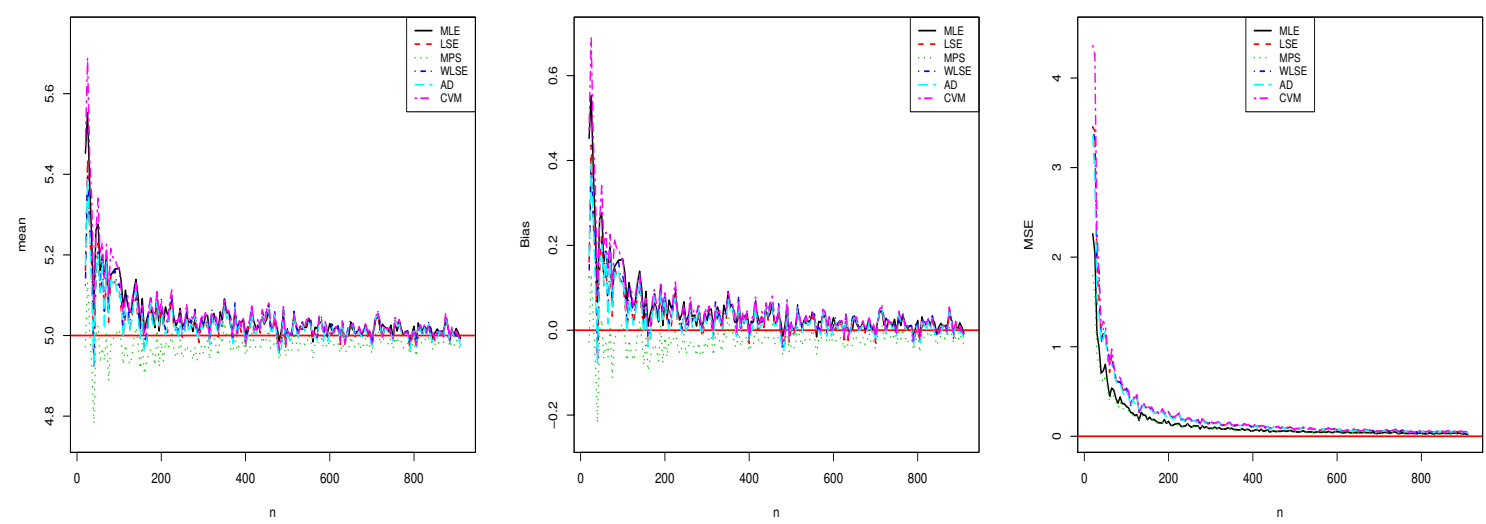

Figure 3. The empirical means, biases and MSEs of the parameter $\beta$

popular in many fields and they are commonly used in statistical software. The AN of MLE can be written by

$$
\widehat{\Xi} \stackrel{d}{\rightarrow} N_{3}\left(\boldsymbol{\Xi}, \mathbb{I}^{-1}(\boldsymbol{\Xi})\right)
$$

where $\widehat{\boldsymbol{\Xi}}$ is MLE of $\boldsymbol{\Xi}$ given in $(8)$ and $\mathbb{I}(\boldsymbol{\Xi})$ is Fisher Information matrix. Using this fact, the $100 \times(1-\gamma) \%$ AN CIs of parameters $\alpha, \beta$ and $\theta$ are constructed, 

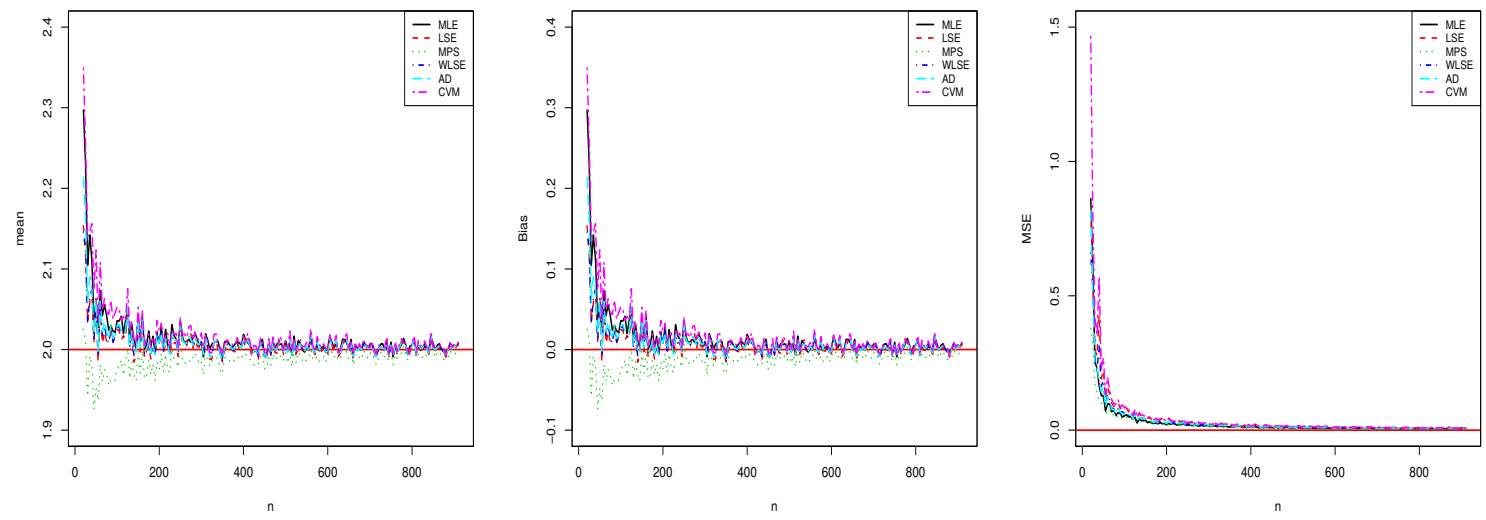

FigurE 4. The empirical means, biases and MSEs of the parameter $\theta$

respectively, by

$$
\begin{aligned}
& \widehat{\alpha} \pm z_{1-\frac{\gamma}{2}} \times s e(\widehat{\alpha}) \\
& \widehat{\beta} \pm z_{1-\frac{\gamma}{2}} \times \operatorname{se}(\widehat{\beta}) \\
& \widehat{\theta} \pm z_{1-\frac{\gamma}{2}} \times \operatorname{se}(\widehat{\theta})
\end{aligned}
$$

where $z_{a}$, is the $a^{\text {th }}$ quantile of the standard normal distribution, se $(\widehat{\alpha})$, se $(\widehat{\beta})$ and $s e(\widehat{\theta})$ are the roots of the diagonal member of $\mathbb{I}^{-1}(\widehat{\boldsymbol{\Xi}})$ which is a consistent estimate of $\mathbb{I}^{-1}(\boldsymbol{\Xi})$ and the $s e(\cdot)$ stands for standard error.

There is another method called uncorrected likelihood ratio (ULR). It is noticed that $\mathrm{AN}$ and ULR CIs are asymptotically equivalent $[10$.

Under usual regularity assumptions on the likelihood function, if the $\alpha$ is true parameter, then $-2 \log (\ell(\alpha, \widetilde{\boldsymbol{\lambda}})-\ell(\widehat{\boldsymbol{\Xi}}))$ distributed as $\chi_{(1)}^{2}$, where $\boldsymbol{\lambda}=(\beta, \theta)$ are the nuisance parameters, $\ell$ is the log-likelihood function as in (7), $\widehat{\boldsymbol{\Xi}}$ is the joint MLE of $(\alpha, \beta, \theta)$ given in $(8), \widetilde{\boldsymbol{\lambda}}=(\widetilde{\beta}, \widetilde{\theta})$ is the restricted MLE of $\boldsymbol{\lambda}$ given a fixed value of $\alpha$. Using this fact, $100 \times(1-\gamma) \%$ ULR CI limits $\alpha_{L}$ and $\alpha_{U}$ that satisfy

$$
\ell(\alpha, \tilde{\boldsymbol{\lambda}})=\underbrace{\ell(\widehat{\boldsymbol{\Xi}})-\frac{1}{2} \chi_{(1)}^{2}(1-\alpha)}_{\text {LR Bound }}
$$


with $\alpha_{L}<\alpha$ and $\alpha_{U}>\alpha$, where $\chi_{(1)}^{2}(a)$ is the $a^{\text {th }}$ quantile of the $\chi^{2}$ distribution with 1 degrees of freedom. The $100 \times(1-\gamma) \%$ ULR CIs can be produced in the same manner for the other parameters $\beta$ and $\theta$.

In the simulation study, 5000 trials are used to predict the coverage probabilities (CPs) of the AN and ULR CIs. The nominal level is fixed at 0.95 . In order to get CPs of ULR CIs, there is no need to obtain the CIs limits. It is possible that the CPs of ULR CIs can be simulated by a likelihood ratio test on the true parameter. The simulated CPs of these intervals are given in Table 2, Let us discuss the true parameter cases $\Xi=(1,1,0.5),(1,1,2.5),(5,5,2),(1,2,3),(3,0.5,1.5)$ and $(2,1,0.25)$. From Table 2 , it is observed that the CPs of ULR reach to the desired level when the all sample of size discussed here (say $n \geq 50$ ) for all parameters. However, the CPs of AN can not reach the desired level for small sample of size case especially for parameter $\beta$. The CPs reach the nominal level when the sample of size increases (say $n \geq 250$ or $n \geq 500$ according to selected true parameters). Under discussion given here, it is indicated that ULR CIs powerful tool to construct the CIs for the MoL parameters.

\section{Real-Life Data Analysis}

In this section, we provide three applications to the real data sets to demonstrate empirically the potentiality of the proposed model. All data sets, we compare the MoL model with MW, PL, GL, EPL, EL and L models. In order to reveal the best model, the estimated log-likelihood values $\ell(\widehat{\boldsymbol{\Xi}})$, Akaike information criteria (AIC), consistent Akaike information criteria (CAIC), Kolmogorov-Smirnov (KS), Cramer von Mises $\left(W^{*}\right)$ and Anderson-Darling $\left(A^{*}\right)$ goodness of-fit statistics are computed for all models.

The first data set represents the times between successive failures (in thousands of hours) in events of secondary reactor pumps studied by [5], [19] and [26]. The data are: $2.160,0.746,0.402,0.954,0.491,6.560,4.992,0.347,0.150,0.358,0.101$, $1.359,3.465,1.060,0.614,1.921,4.082,0.199,0.605,0.273,0.070,0.062,5.320$.

The second data for breaking stress of carbon fibers of $50 \mathrm{~mm}$ length (GPa) was studied in 23. The data are: $0.39,0.85,1.08,1.25,1.47,1.57,1.61,1.61,1.69,1.80$, $1.84,1.87,1.89,2.03,2.03,2.05,2.12,2.35,2.41,2.43,2.48,2.50,2.53,2.55,2.55$, $2.56,2.59,2.67,2.73,2.74,2.79,2.81,2.82,2.85,2.87,2.88,2.93,2.95,2.96,2.97$, $3.09,3.11,3.11,3.15,3.15,3.19,3.22,3.22,3.27,3.28,3.31,3.31,3.33,3.39,3.39$, $3.56,3.60,3.65,3.68,3.70,3.75,4.20,4.38,4.42,4.70,4.90$.

The third data reported in 7 which corresponds to the survival times (in years) of a group of patients given chemotherapy treatment alone. The data consisting of survival times (in years) for 45 patients are: $0.047,0.115,0.121,0.132,0.164$, $0.197,0.203,0.260,0.282,0.296,0.334,0.395,0.458,0.466,0.501,0.507,0.529$, $0.534,0.540,0.641,0.644,0.696,0.841,0.863,1.099,1.219,1.271,1.326,1.447$, $1.485,1.553,1.581,1.589,2.178,2.343,2.416,2.444,2.825,2.830,3.578,3.658$, $3.743,3.978,4.003,4.033$. 
TABle 2. The CPs of AN and ULR CIs

\begin{tabular}{|c|c|c|c|c|c|c|c|c|c|}
\hline \multicolumn{4}{|c|}{ True parameter } & \multicolumn{3}{|c|}{$\mathrm{AN}$} & \multicolumn{3}{|c|}{ ULR } \\
\hline$\alpha$ & $\beta$ & $\theta$ & $n$ & $\alpha$ & $\beta$ & $\theta$ & $\alpha$ & $\beta$ & $\theta$ \\
\hline \multirow[t]{5}{*}{1} & 1 & 0.5 & 50 & 0.9480 & 0.8698 & 0.9390 & 0.9472 & 0.9412 & 0.9480 \\
\hline & & & 100 & 0.9462 & 0.8848 & 0.9354 & 0.9474 & 0.9366 & 0.9444 \\
\hline & & & 250 & 0.9488 & 0.9294 & 0.9472 & 0.9494 & 0.9430 & 0.9508 \\
\hline & & & 500 & 0.9476 & 0.9394 & 0.9500 & 0.9468 & 0.9438 & 0.9494 \\
\hline & & & 1000 & 0.9502 & 0.9484 & 0.9520 & 0.9500 & 0.9510 & 0.9526 \\
\hline \multirow[t]{5}{*}{1} & 1 & 2.5 & 50 & 0.9514 & 0.8840 & 0.9688 & 0.9374 & 0.9544 & 0.9556 \\
\hline & & & 100 & 0.9524 & 0.9174 & 0.9618 & 0.9464 & 0.9534 & 0.9468 \\
\hline & & & 250 & 0.9484 & 0.9386 & 0.9514 & 0.9466 & 0.9492 & 0.9422 \\
\hline & & & 500 & 0.9470 & 0.9470 & 0.9494 & 0.9480 & 0.9520 & 0.9450 \\
\hline & & & 1000 & 0.9488 & 0.9470 & 0.9486 & 0.9488 & 0.9498 & 0.9464 \\
\hline \multirow[t]{5}{*}{5} & 5 & 2 & 50 & 0.9480 & 0.9428 & 0.9472 & 0.9420 & 0.9392 & 0.9456 \\
\hline & & & 100 & 0.9464 & 0.9444 & 0.9500 & 0.9444 & 0.9430 & 0.9458 \\
\hline & & & 250 & 0.9464 & 0.9498 & 0.9482 & 0.9452 & 0.9498 & 0.9472 \\
\hline & & & 500 & 0.9548 & 0.9506 & 0.9522 & 0.9534 & 0.9502 & 0.9510 \\
\hline & & & 1000 & 0.9554 & 0.9544 & 0.9518 & 0.9554 & 0.9544 & 0.9502 \\
\hline \multirow[t]{5}{*}{1} & 2 & 3 & 50 & 0.9474 & 0.8976 & 0.9712 & 0.9396 & 0.9368 & 0.9422 \\
\hline & & & 100 & 0.9468 & 0.9310 & 0.9602 & 0.9414 & 0.9496 & 0.9454 \\
\hline & & & 250 & 0.9496 & 0.9380 & 0.9566 & 0.9464 & 0.9428 & 0.9488 \\
\hline & & & 500 & 0.9428 & 0.9462 & 0.9472 & 0.9430 & 0.9474 & 0.9442 \\
\hline & & & 1000 & 0.9544 & 0.9482 & 0.9506 & 0.9554 & 0.9478 & 0.9508 \\
\hline \multirow[t]{5}{*}{3} & 0.5 & 1.5 & 50 & 0.9276 & 0.8896 & 0.9426 & 0.9326 & 0.9426 & 0.9698 \\
\hline & & & 100 & 0.9324 & 0.9120 & 0.9360 & 0.9422 & 0.9516 & 0.9674 \\
\hline & & & 250 & 0.9444 & 0.9490 & 0.9502 & 0.9548 & 0.9680 & 0.9688 \\
\hline & & & 500 & 0.9422 & 0.9514 & 0.9592 & 0.9526 & 0.9608 & 0.9582 \\
\hline & & & 1000 & 0.9492 & 0.9638 & 0.9580 & 0.9542 & 0.9558 & 0.9486 \\
\hline \multirow[t]{5}{*}{2} & 1 & 0.25 & 50 & 0.9580 & 0.8750 & 0.9472 & 0.9580 & 0.9500 & 0.9584 \\
\hline & & & 100 & 0.9572 & 0.8886 & 0.9510 & 0.9614 & 0.9480 & 0.9586 \\
\hline & & & 250 & 0.9444 & 0.9164 & 0.9428 & 0.9458 & 0.9376 & 0.9452 \\
\hline & & & 500 & 0.9444 & 0.9390 & 0.9464 & 0.9446 & 0.9504 & 0.9466 \\
\hline & & & 1000 & 0.9538 & 0.9478 & 0.9510 & 0.9540 & 0.9494 & 0.9510 \\
\hline
\end{tabular}


We give the summary statistics of the data sets in Table 3. The first and third data sets have right skewness as well as the second data set has the left skewness.

TABLE 3. Some summary statistics of the data sets

\begin{tabular}{cccccc}
\hline Data set & Mean & Median & Standard Deviation & Skewness & Kurtosis \\
\hline \hline I & 1.5780 & 0.6140 & 1.9306 & 1.3643 & 3.5445 \\
\hline II & 2.7600 & 2.8350 & 0.8914 & -0.1314 & 3.2230 \\
\hline III & 1.3410 & 0.8410 & 1.2466 & 0.9721 & 2.6638 \\
\hline \hline
\end{tabular}

Tables 4 [1 list the MLEs, standard errors, $\ell(\widehat{\Xi})$ and goodness-of-fits statistics from the fitted models. Tables 446 show that the MoL model can be chosen as the best model based on all criteria. In addition, we give the parameter estimation results and goodness-of-fit statistics of the MoL distribution based on other estimation methods in Table 7. Figures 5 7 show the fitted densities, cdfs and probability-probability (P-P) plots of the MoL model. We also sketch the P-P plots of others models in Figures 8 10. From Figures 8 10, we clearly show that the MoL model fits this data set better than the other models.

TABLE 4. MLEs, standard erros of the estimates (in parentheses), $\hat{\ell}$, goodness-of-fits statistics and related $p$-values [in parentheses] for the first data set

\begin{tabular}{cllllccccc}
\hline \hline Model & $\widehat{\alpha}$ & $\widehat{\beta}$ & $\widehat{\theta}$ & $-\hat{\ell}$ & $A I C$ & $C A I C$ & $K S$ & $A^{*}$ & $W^{*}$ \\
\hline MoL & 0.8148 & 1.7119 & 0.9419 & 31.3782 & 68.7565 & 70.0196 & 0.0785 & 0.1881 & 0.0204 \\
& $(0.1582)$ & $(2.0132)$ & $(0.2169)$ & & & & {$[0.9967]$} & {$[0.9934]$} & {$[0.9972]$} \\
MW & 0.7922 & 0.0093 & 0.7517 & 32.5082 & 71.0165 & 72.2796 & 0.1198 & 0.4141 & 0.0639 \\
& $(0.1925)$ & $(0.0850)$ & $(0.2199)$ & & & & {$[0.8575]$} & {$[0.8330]$} & {$[0.7939]$} \\
PL & 0.7253 & & 1.1948 & 32.7476 & 69.4952 & 70.0952 & 0.1189 & 0.4279 & 0.0643 \\
& $(0.1129)$ & & $(0.2119)$ & & & & {$[0.8628]$} & {$[0.8190]$} & {$[0.7918]$} \\
GL & 0.7457 & 0.00016 & 0.4728 & 32.7592 & 71.5184 & 72.7815 & 0.1379 & 0.5236 & 0.0889 \\
& $(0.1885)$ & $(0.0116)$ & $(0.1659)$ & & & & {$[0.7293]$} & {$[0.7209]$} & {$[0.6462]$} \\
EL & 0.6130 & & 0.7251 & 33.4889 & 70.9779 & 71.5779 & 0.1558 & 0.7059 & 0.1246 \\
& $(0.1647)$ & & $(0.1782)$ & & & & {$[0.5784]$} & {$[0.5521]$} & {$[0.4799]$} \\
EPL & 0.2770 & 11.5880 & 3.7238 & 31.8359 & 69.6718 & 70.9349 & 0.0963 & 0.2264 & 0.0253 \\
& $(0.2404)$ & $(32.7190)$ & $(2.9916)$ & & & & {$[0.9691]$} & {$[0.9814]$} & {$[0.9903]$} \\
L & & & 0.9575 & 35.3054 & 72.6107 & 72.8013 & 0.2439 & 2.2967 & 0.3821 \\
& & & $(0.1504)$ & & & & {$[0.1085]$} & {$[0.0640]$} & {$[0.0798]$} \\
\hline \hline
\end{tabular}

In Table 8, 95\% AN and ULR confidence limits of the parameters are presented for the all data sets. In general the limits of AN and ULR intervals are close to each other. Figure 11 demonstrate the ULR intervals for the third real data. 
TABle 5. MLEs, standard erros of the estimates (in parentheses), $\hat{\ell}$, goodness-of-fits statistics and related $p$-values [in parentheses] for the second data set

\begin{tabular}{|c|c|c|c|c|c|c|c|c|c|}
\hline Model & $\overline{\widehat{\alpha}}$ & $\widehat{\beta}$ & $\widehat{\theta}$ & $-\hat{\ell}$ & $A I C$ & $\overline{C A I C}$ & $K S$ & $A^{*}$ & $W^{*}$ \\
\hline MoL & $\begin{array}{c}2.7039 \\
(0.2170)\end{array}$ & $\begin{array}{c}0.7905 \\
(0.4304)\end{array}$ & $\begin{array}{c}0.0967 \\
(0.0257)\end{array}$ & 85.6419 & 177.2838 & 177.6709 & $\begin{array}{c}0.0741 \\
{[0.8607]}\end{array}$ & $\begin{array}{c}0.3956 \\
{[0.8526]}\end{array}$ & $\begin{array}{c}0.0620 \\
{[0.8025]}\end{array}$ \\
\hline MW & $\begin{array}{c}2.1535 \\
(1.0622)\end{array}$ & $\begin{array}{c}0.4302 \\
(0.3581)\end{array}$ & $\begin{array}{c}0.0228 \\
(0.0092)\end{array}$ & 85.9866 & 177.9732 & 178.3603 & $\begin{array}{c}0.0905 \\
{[0.6519]}\end{array}$ & $\begin{array}{c}0.5266 \\
{[0.7192]}\end{array}$ & $\begin{array}{c}0.0838 \\
{[0.6719]}\end{array}$ \\
\hline PL & $\begin{array}{c}2.5099 \\
(0.2088)\end{array}$ & & $\begin{array}{c}0.1241 \\
(0.0311)\end{array}$ & 85.8055 & 175.6111 & 175.8015 & $\begin{array}{c}0.0790 \\
{[0.8051]}\end{array}$ & $\begin{array}{c}0.4651 \\
{[0.7820]}\end{array}$ & $\begin{array}{c}0.0819 \\
{[0.6824]}\end{array}$ \\
\hline GL & $\begin{array}{c}6.9574 \\
(1.4779\end{array}$ & $\begin{array}{c}8.0712 \\
(21.2598)\end{array}$ & $\begin{array}{c}2.7905 \\
(0.4860)\end{array}$ & 90.9276 & 187.8552 & 188.2423 & $\begin{array}{c}0.1318 \\
{[0.2014]}\end{array}$ & $\begin{array}{c}1.2861 \\
{[0.2368]}\end{array}$ & $\begin{array}{c}0.2420 \\
{[0.1991]}\end{array}$ \\
\hline EL & $\begin{array}{c}7.0411 \\
(1.6730)\end{array}$ & & $\begin{array}{c}1.2461 \\
(0.1090)\end{array}$ & 93.7970 & 191.5939 & 191.7844 & $\begin{array}{c}0.1470 \\
{[0.1154]}\end{array}$ & $\begin{array}{c}1.8375 \\
{[0.1132]}\end{array}$ & $\begin{array}{c}0.3284 \\
{[0.1124]}\end{array}$ \\
\hline EPL & $\begin{array}{c}3.1439 \\
(0.8257)\end{array}$ & $\begin{array}{c}0.6238 \\
(0.3149)\end{array}$ & $\begin{array}{c}0.0458 \\
(0.0585)\end{array}$ & 85.4258 & 176.8516 & 177.2387 & $\begin{array}{c}0.0772 \\
{[0.8258]}\end{array}$ & $\begin{array}{c}0.4094 \\
{[0.8388]}\end{array}$ & $\begin{array}{c}0.0683 \\
{[0.7638]}\end{array}$ \\
\hline $\mathrm{L}$ & & & $\begin{array}{c}0.5903 \\
(0.0532) \\
\end{array}$ & 122.3841 & 246.7681 & 246.8306 & $\begin{array}{c}0.2977 \\
{[0.0000]} \\
\end{array}$ & $\begin{array}{l}10.6922 \\
{[0.0000]}\end{array}$ & $\begin{array}{c}2.0914 \\
{[0.0000]}\end{array}$ \\
\hline
\end{tabular}

TABLE 6. MLEs, standard erros of the estimates (in parentheses), $\hat{\ell}$, goodness-of-fits statistics and related $p$-values [in parentheses] for the third data set

\begin{tabular}{|c|c|c|c|c|c|c|c|c|c|}
\hline Model & $\widehat{\alpha}$ & $\widehat{\beta}$ & $\widehat{\theta}$ & $-\hat{\ell}$ & $A I C$ & $C A I C$ & $K S$ & $A^{*}$ & $W^{*}$ \\
\hline $\mathrm{MoL}$ & $\begin{array}{c}1.1610 \\
(0.1378)\end{array}$ & $\begin{array}{c}2.5389 \\
(0.7903)\end{array}$ & $\begin{array}{c}0.8263 \\
(0.1309)\end{array}$ & 55.8323 & 117.6647 & 118.250 & $\begin{array}{c}0.0661 \\
{[0.9819]}\end{array}$ & $\begin{array}{c}0.3437 \\
{[0.9015]}\end{array}$ & $\begin{array}{c}0.0393 \\
{[0.9388}\end{array}$ \\
\hline MW & $\begin{array}{c}0.9677 \\
(0.2047)\end{array}$ & $\begin{array}{c}0.0620 \\
(0.1235)\end{array}$ & $\begin{array}{c}0.6529 \\
(0.1702)\end{array}$ & 57.9942 & 121.9885 & 122.5738 & $\begin{array}{c}0.1116 \\
{[0.5958]}\end{array}$ & $\begin{array}{c}0.5700 \\
{[0.6758]}\end{array}$ & $\begin{array}{c}0.0864 \\
{[0.6577]}\end{array}$ \\
\hline PL & $\begin{array}{c}0.9465 \\
(0.1076)\end{array}$ & & $\begin{array}{c}1.1351 \\
(0.1465)\end{array}$ & 58.4028 & 120.8056 & 121.0913 & $\begin{array}{c}0.1104 \\
{[0.6033]}\end{array}$ & $\begin{array}{c}0.5656 \\
{[0.6801]}\end{array}$ & $\begin{array}{c}0.0845 \\
{[0.6683]}\end{array}$ \\
\hline GL & $\begin{array}{c}1.0931 \\
(0.2256)\end{array}$ & $\begin{array}{c}0.8896 \\
(0.4456)\end{array}$ & $\begin{array}{c}0.0991 \\
(0.7380)\end{array}$ & 58.0862 & 122.1725 & 122.7578 & $\begin{array}{c}0.1110 \\
{[0.5967]}\end{array}$ & $\begin{array}{c}0.5482 \\
{[0.6973]}\end{array}$ & $\begin{array}{c}0.0842 \\
{[0.6702]}\end{array}$ \\
\hline EL & $\begin{array}{c}0.9412 \\
(0.1919)\end{array}$ & & $\begin{array}{c}1.0656 \\
(0.1693)\end{array}$ & 58.4784 & 120.9568 & 121.2425 & $\begin{array}{c}0.1196 \\
{[0.5026]}\end{array}$ & $\begin{array}{c}0.6498 \\
{[0.6013]}\end{array}$ & $\begin{array}{c}0.1015 \\
{[0.5794]}\end{array}$ \\
\hline EPL & $\begin{array}{c}0.6579 \\
(0.3390)\end{array}$ & $\begin{array}{c}2.0911 \\
(2.2867)\end{array}$ & $\begin{array}{c}1.8562 \\
(1.1306)\end{array}$ & 58.1167 & 122.2333 & 122.8187 & $\begin{array}{c}0.0972 \\
{[0.7521]}\end{array}$ & $\begin{array}{c}0.4736 \\
{[0.7729]}\end{array}$ & $\begin{array}{c}0.0702 \\
{[0.7530]}\end{array}$ \\
\hline $\mathrm{L}$ & & & $\begin{array}{c}1.1004 \\
(0.1249)\end{array}$ & 58.5231 & 119.0461 & 119.1391 & $\begin{array}{c}0.1304 \\
{[0.3964]}\end{array}$ & $\begin{array}{c}0.7721 \\
{[0.5007]}\end{array}$ & $\begin{array}{c}0.1253 \\
{[0.4758]}\end{array}$ \\
\hline
\end{tabular}

TABLE 7. The different estimations results of the MoL model parameters for the data sets

\begin{tabular}{|c|c|c|c|c|c|c|c|c|c|c|c|c|c|c|c|c|c|c|}
\hline \multirow[b]{2}{*}{ Method } & \multicolumn{6}{|c|}{$\begin{array}{l}\text { Data set-I } \\
\end{array}$} & \multicolumn{6}{|c|}{ 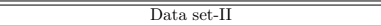 } & \multicolumn{6}{|c|}{ "Data set-III } \\
\hline & $\widehat{\alpha}$ & $\bar{\beta}$ & $\ddot{\theta}$ & $A^{*}$ & $W^{*}$ & $K S$ & $\widehat{\alpha}$ & $\tilde{\beta}$ & $\tilde{\theta}$ & $A^{*}$ & $W^{*}$ & $K S$ & $\widehat{\alpha}$ & $\bar{\beta}$ & $\tilde{\theta}$ & $A^{*}$ & $W^{*}$ & $K S$ \\
\hline LSE & 0.6773 & 1.5845 & 0.9559 & 0.1593 & 0.0132 & 0.0677 & 2.9451 & 1.9433 & 0.0748 & 0.4434 & 0.0668 & 0.0701 & 1.0068 & 2.0508 & 0.8411 & 0.2629 & 0.0301 & 0.0626 \\
\hline WLSE & 0.7205 & 1.8431 & 0.9376 & 0.1554 & 0.0131 & 0.0689 & 2.5905 & 0.0144 & 0.1124 & 0.5642 & 0.1054 & 0.0898 & 1.0586 & 2.1764 & 0.8467 & 0.2873 & 0.0369 & 0.0658 \\
\hline $\mathrm{AD}$ & 0.7659 & 1.9442 & 0.9314 & 0.1417 & 0.0131 & 0.0595 & \begin{tabular}{|l|}
2.8612 \\
\end{tabular} & 1.4052 & 0.0815 & 0.3394 & 0.0408 & 0.0661 & \begin{tabular}{|l|l|}
1.0537 \\
\end{tabular} & 2.1279 & 0.8455 & 0.2619 & 0.0292 & 0.0642 \\
\hline CVM & 0.7315 & 1.6954 & 0.9514 & 0.1481 & 0.0124 & 0.0666 & 2.9952 & 1.6715 & 0.0712 & 0.3852 & 0.0354 & 0.0585 & \begin{tabular}{|l|l|}
1.0479 \\
\end{tabular} & 2.1197 & 0.8354 & 0.2673 & 0.0283 & 0.0683 \\
\hline
\end{tabular}


MODIFIED-LINDLEY DISTRIBUTION AND ITS APPLICATIONS TO THE REAL DATA265

TABle 8. Confidence limits for parameters $\alpha, \beta$ and $\theta$ based on AN and ULR for the data sets

\begin{tabular}{lllllll}
\hline Data & AN & \multicolumn{5}{l}{ ULR } \\
\hline \multicolumn{1}{c}{$\alpha$} & $\beta$ & $\theta$ & $\alpha$ & $\beta$ & $\theta$ \\
\hline Data set-I & $(0.5051,1.1247)$ & $(-2.2231,5.6466)$ & $(0.5167,1.3669)$ & $(0.5628,1.1177)$ & $(0,4.6380)$ & $(0.5967,1.3985)$ \\
Data set-II & $(2.2759,3.1253)$ & $(-0.0451,1.6400)$ & $(0.0465,0.1470)$ & $(2.1268,3.1366)$ & $(0,3.2554)$ & $(0.0565,0.1991)$ \\
Data set-III & $(0.8909,1.4311)$ & $(0.9898,4.0880)$ & $(0.5695,1.0830)$ & $(0.9069,1.4431)$ & $(1.1613,3.9695)$ & $(0.5983,1.1126)$ \\
\hline
\end{tabular}
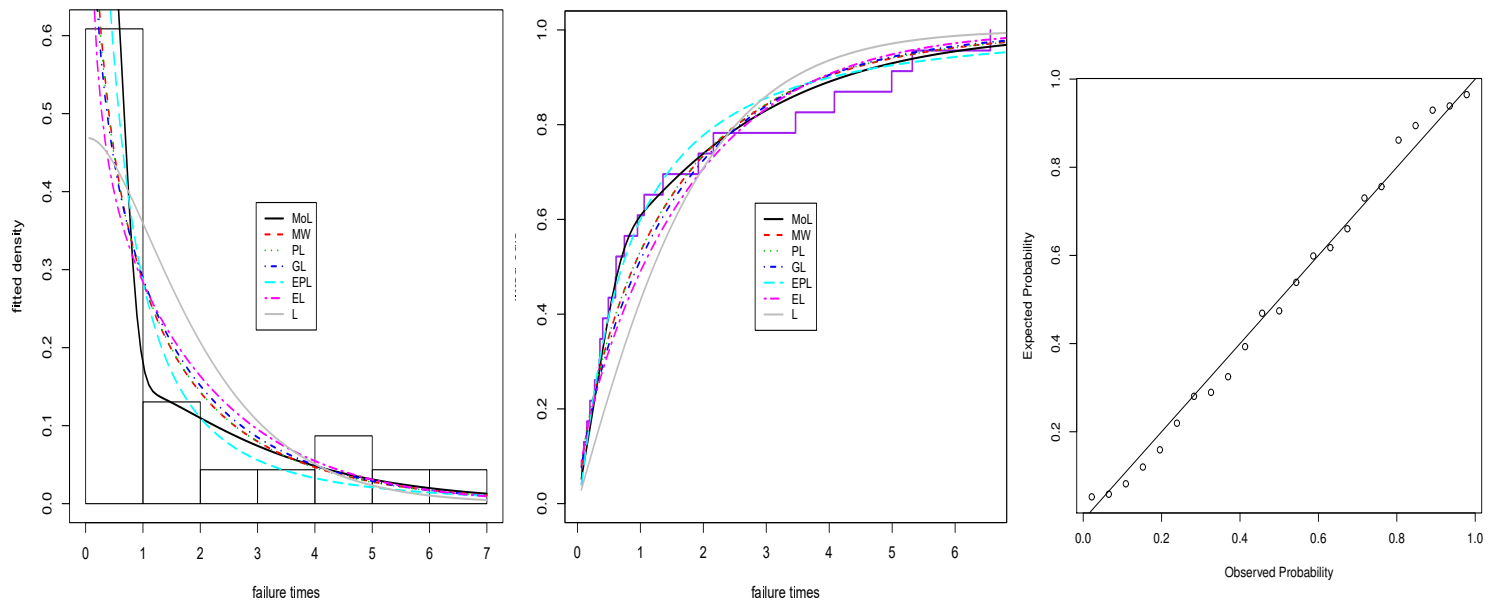

Figure 5. The fitted plots for the first data set
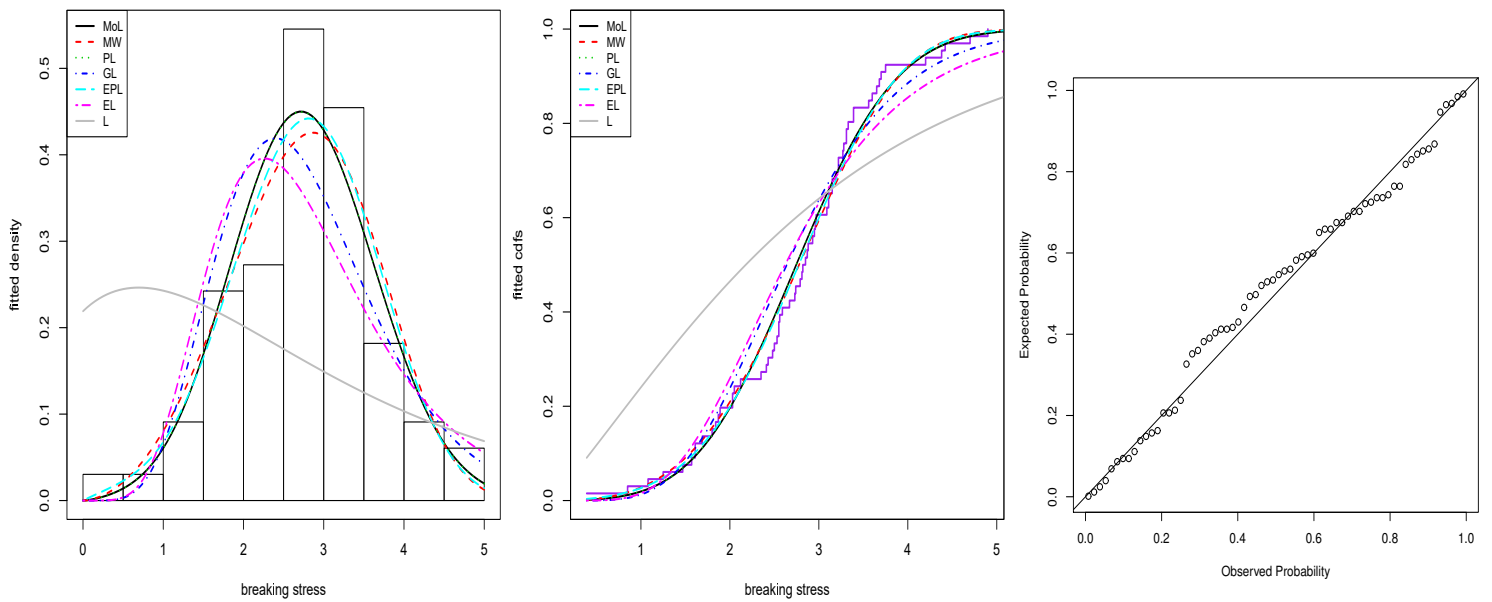

Figure 6 . The fitted plots for the second data set 

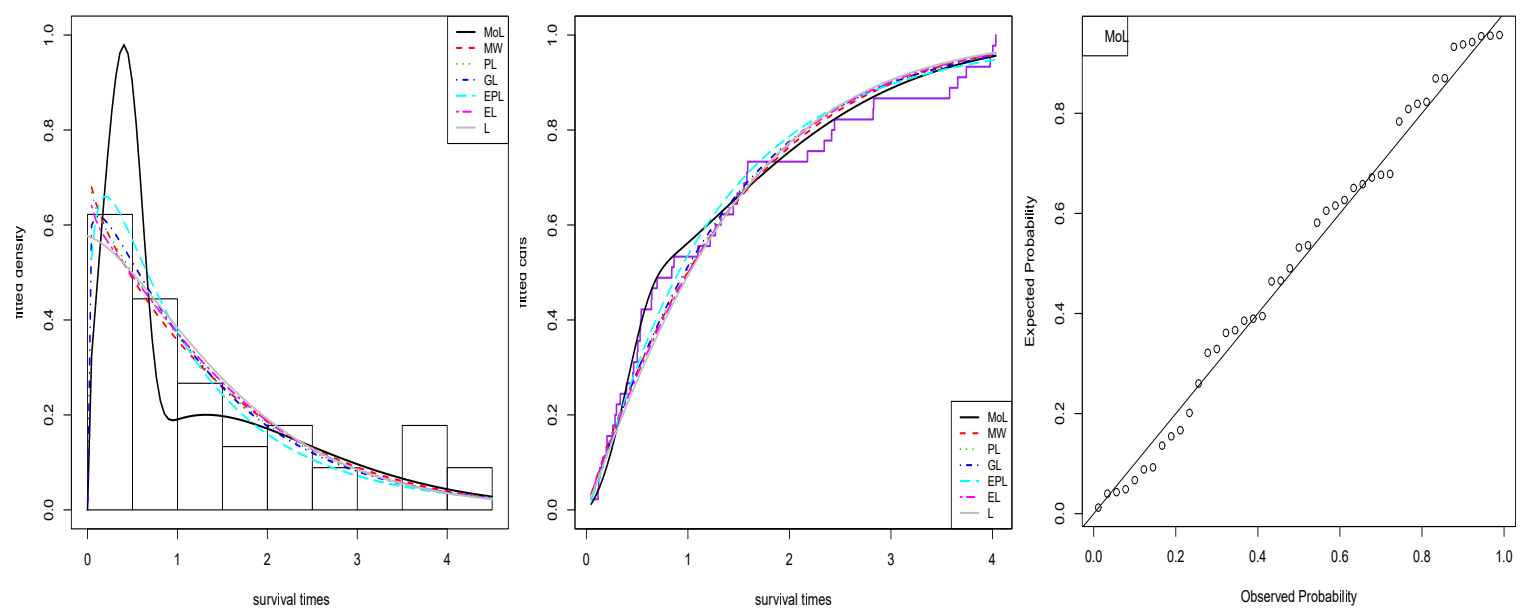

Figure 7. The fitted plots for the third data set

Author Contribution Statements The authors jointly worked on the results and they read and approved the final manuscript.

Declaration of Competing Interests The authors declare that they have no competing interest.

\section{Appendix}

Proof of Theorem 1.

The pdf of the $X$ is

$$
f(x)=\frac{\theta}{\theta+1} g_{1}(x ; \alpha, \beta, \theta)+\frac{1}{\theta+1} g_{2}(x ; \alpha, \beta, \theta)
$$

Get the $W(x)$ density ratio of MoL distribution in two parts as $W_{1}(x)$ and $W_{2}(x)$. If $W_{1}(x)$ and $W_{2}(x)$ density ratios are increasing functions in $x$, the $W(x)$ density ratio is also an increasing function of $x$. The $W_{1}(x)$ and $W_{2}(x)$ ratios are given by

$$
W_{1}(x)=\frac{g_{1}\left(x ; \alpha, \beta, \theta_{1}\right)}{g_{1}\left(x ; \alpha, \beta, \theta_{2}\right)}
$$

and

$$
W_{2}(x)=\frac{g_{2}\left(x ; \alpha, \beta, \theta_{1}\right)}{g_{2}\left(x ; \alpha, \beta, \theta_{2}\right)}
$$

where $g_{1}(x ; \alpha, \beta, \theta)$ and $g_{2}(x ; \alpha, \beta, \theta)$ are the pdfs of MW and GG distributions respectively. Firstly, the MW density ratio is given by

$$
W_{1}(x)=\frac{g_{1}\left(x ; \alpha, \beta, \theta_{1}\right)}{g_{1}\left(x ; \alpha, \beta, \theta_{2}\right)}=\frac{\theta_{1} \exp \left(\beta x-\theta_{1} x^{\alpha} \exp (\beta x)\right)}{\theta_{2} \exp \left(\beta x-\theta_{2} x^{\alpha} \exp (\beta x)\right)}
$$



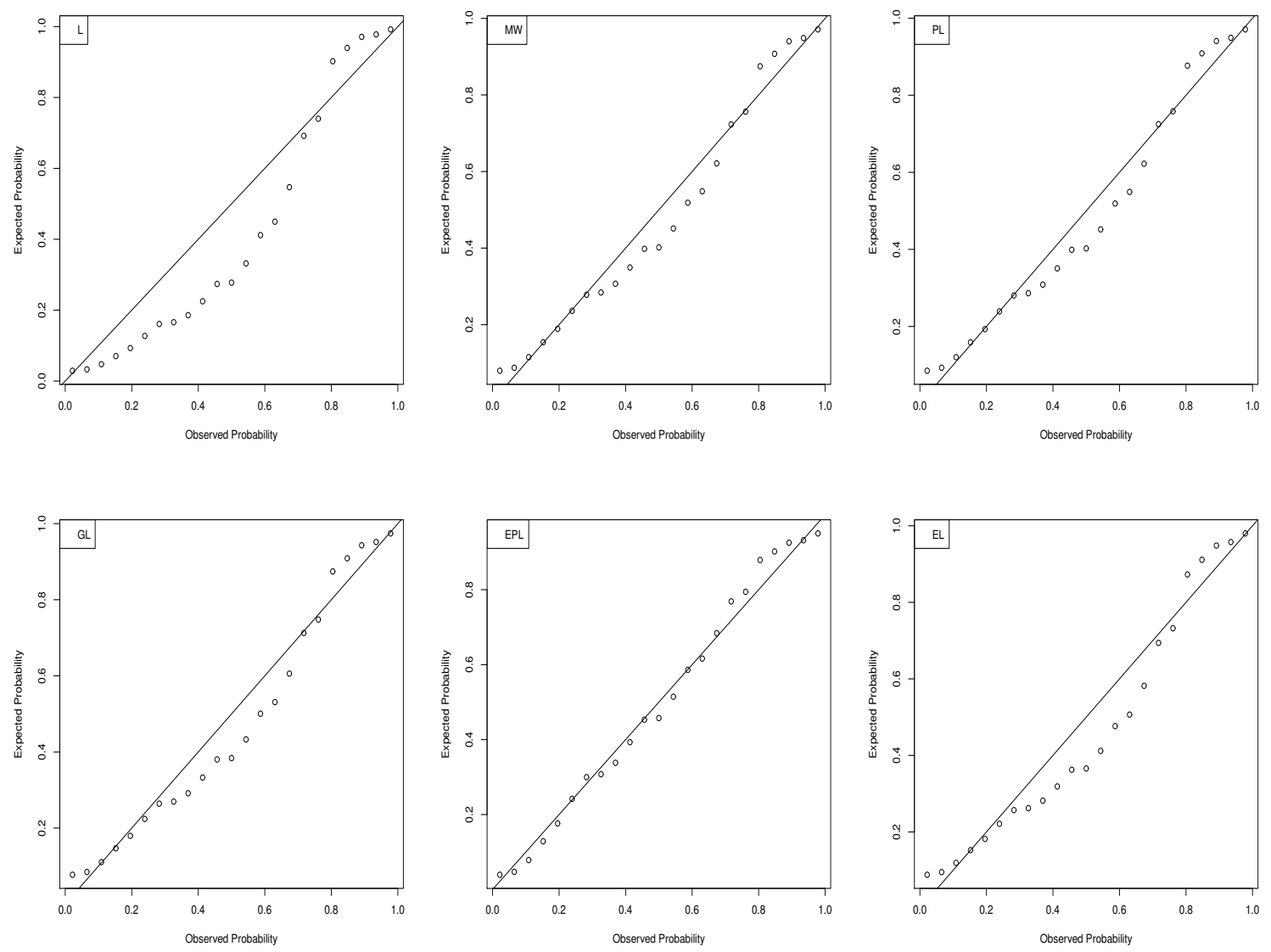

Figure 8. The PP plots for the first data set

Taking the derivative with respect to $x$,

$$
W_{1}^{\prime}(x)=-\frac{\overbrace{\theta_{1} x^{\alpha} \exp (\beta x)(\alpha+\beta x) \exp \left(\beta x-\theta_{1} x^{\alpha} \exp (\beta x)\right)}^{>0}\left(\theta_{1}-\theta_{2}\right)}{\underbrace{x \theta_{2} \exp \left(\beta x-\theta_{2} x^{\alpha} \exp (\beta x)\right)}_{>0}}
$$

for $\theta_{1}<\theta_{2},-\left(\left(\theta_{1}-\theta_{2}\right)\right)$ is greater than zero. So $W_{1}^{\prime}(x)>0$ when $\theta_{1}<\theta_{2}$ is taken. $W_{1}(x)$ is an increasing function in $x$. Secondly, the same steps are applied 

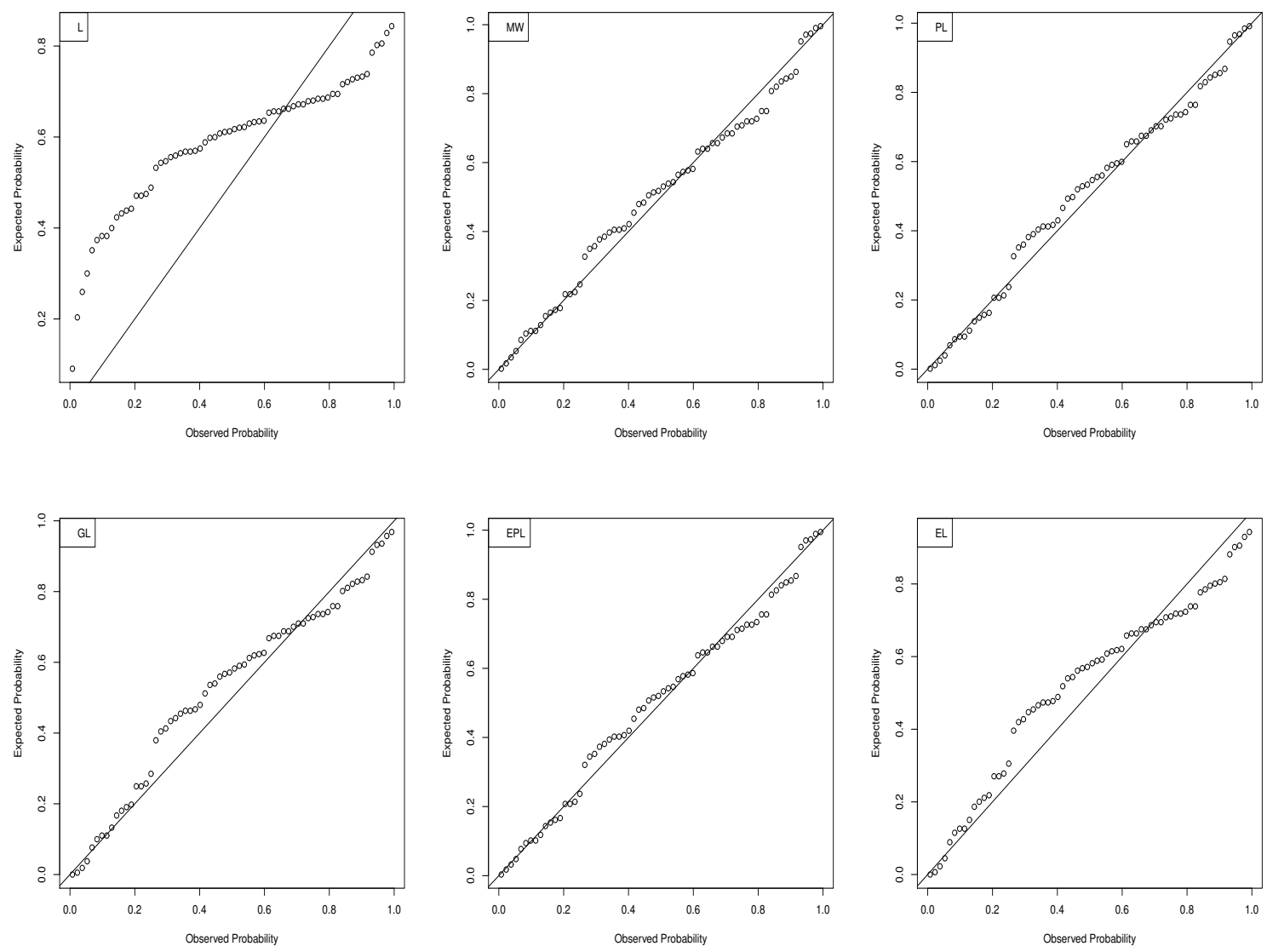

Figure 9. The PP plots for the second data set

for GG density ratio. The GG density ratio is given by

$$
W_{2}(x)=\frac{g_{2}\left(x ; \alpha, \beta, \theta_{1}\right)}{g_{2}\left(x ; \alpha, \beta, \theta_{2}\right)}=\frac{\theta_{1}^{2} \exp \left(-\theta_{1} x^{\alpha}\right)}{\theta_{2}^{2} \exp \left(-\theta_{2} x^{\alpha}\right)}
$$

Taking the derivative with respect to $x$,

$$
W_{2}^{\prime}(x)=-\frac{\overbrace{\theta_{1}^{2} \exp \left(-\theta_{1} x^{\alpha}\right) x^{\alpha} \alpha}\left(\theta_{1}-\theta_{2}\right)}{\underbrace{x 0}_{>0} \underbrace{2}_{2} \exp \left(-\theta_{2} x^{\alpha}\right)}
$$



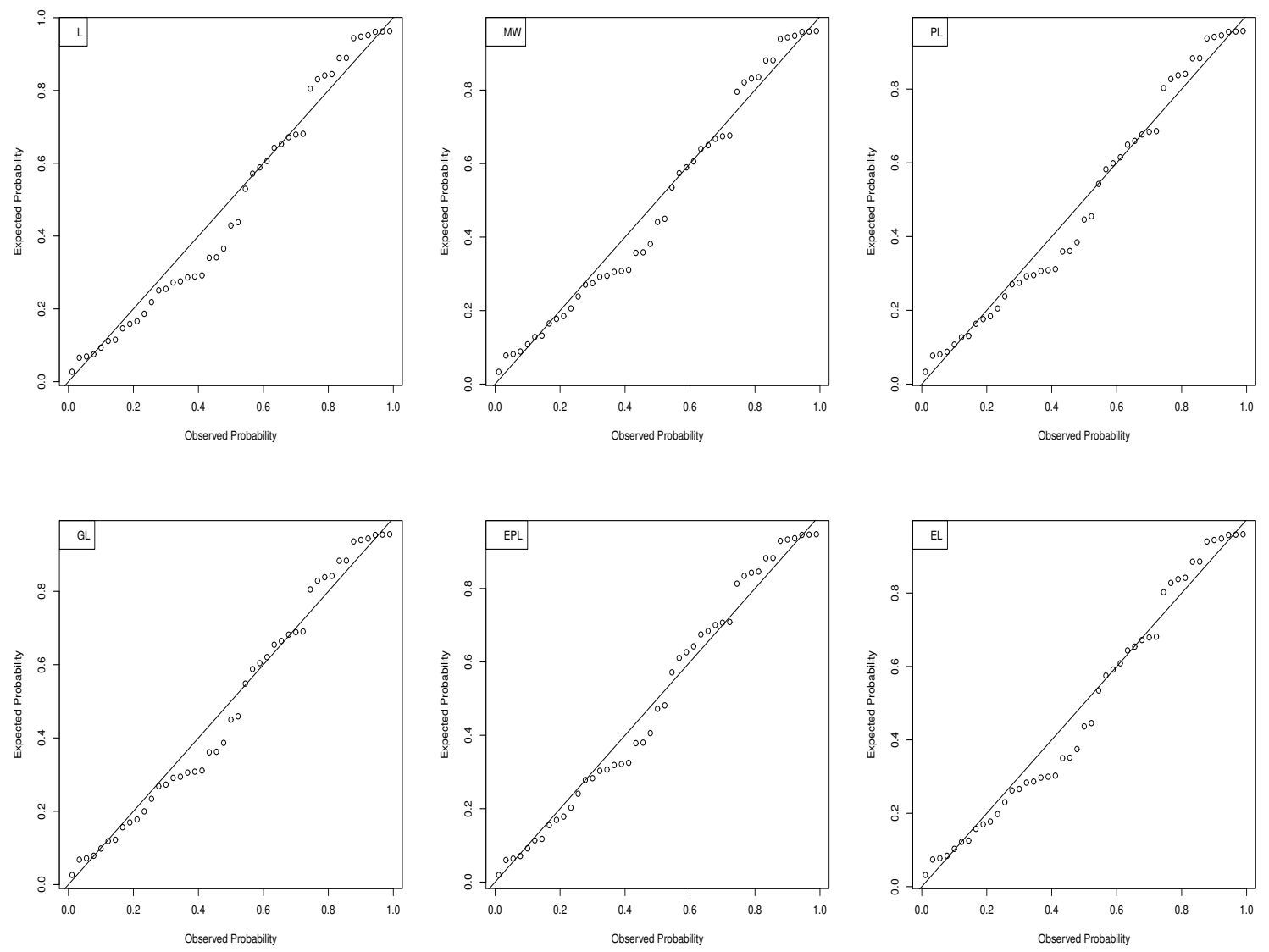

Figure 10. The PP plots for the third data set

for $\theta_{1}<\theta_{2},-\left(\left(\theta_{1}-\theta_{2}\right)\right)$ is greater than zero. So $W_{2}^{\prime}(x)>0$ when $\theta_{1}<\theta_{2}$. $W_{2}(x)$ is an increasing function in $x$. Since both $W_{1}(x)$ and $W_{2}(x)$ are increasing functions in $x, W(x)=W_{1}(x)+W_{2}(x)$ is also an increasing function in $x$. The proof is completed.

Proof of Theorem 2

Using the fact that mixed representation MoL pdf given in (2), the $r$ th moment, $\mu_{r}^{\prime}=E\left(X^{r}\right)$, of the MoL distribution can be written by 



FiguRE 11. ULR confidence limits for parameters $\alpha, \beta$ and $\theta$ for the real data III

$$
\mu_{r}^{\prime}=\frac{\theta}{\theta+1} E\left(X_{M W}^{r}\right)+\frac{1}{\theta+1} E\left(X_{G G}^{r}\right)
$$

where

$$
E\left(X_{G G}^{r}\right)=\Gamma(r / \alpha+2) \theta^{-r / \alpha}
$$

is the $r$ th moment of GG distribution and

$$
E\left(X_{M W}^{r}\right)=\sum_{i_{1}, \ldots, i_{r}=1}^{\infty} A_{i_{1}, \ldots, i_{r}} \Gamma\left(s_{r} / \alpha+1\right) \theta^{-s_{r} / \alpha},
$$

is the $r$ th moment of the MW distribution [8] with

$$
A_{i_{1}, \ldots, i_{r}}=a_{i_{1}}, \ldots, a_{i_{r}}, s_{r}=i_{1}+\cdots+i_{r}
$$

and

$$
a_{i}=(-1)^{i+1} i^{i-2} \beta^{i-1}\left[\alpha^{i-1}(i-1) !\right]^{-1} .
$$

The proof is completed by using 21 and 22, in 20,

$$
\mu_{r}^{\prime}=\frac{1}{\theta+1}\left[\Gamma(r / \alpha+2) \theta^{-r / \alpha}+\sum_{i_{1}, \ldots, i_{r}=1}^{\infty} A_{i_{1}, \ldots, i_{r}} \Gamma\left(s_{r} / \alpha+1\right) \theta^{1-s_{r} / \alpha}\right] .
$$




\section{REFERENCES}

[1] Alizadeh, M., MirMostafaee, S. M. T. K., Ghosh, I., A new extension of power Lindley distribution for analyzing bimodal data, Chilean Journal of Statistics, 8(1) (2017), 67-86.

[2] Almazah, M. M. A., Erbayram, T., Akdoğan, Y., Al Sobhi, M. M., Afify, A. Z., A new extended geometric distribution: properties, regression model, and actuarial applications, Mathematics, 9(12) (2021), 1336. https://doi.org/10.3390/math9121336

[3] Altun, G., Alizadeh, M., Altun, E., Ozel, G., Odd Burr Lindley distribution with properties and applications, Hacettepe Journal of Mathematics and Statistics, 46(2) (2017), 255-276. https://doi.org/10.15672/HJMS.2017.410

[4] Asgharzadeh, A., Nadarajah, S., Sharafi, F., Weibull Lindley distribution, REVSTAT Statistical Journal, 16 (2018), 87-113.

[5] Bebbington, M., Lai, C. D., Zitikis, R., A flexible Weibull extension, Reliability Engineering and System Safety, 92(6) (2007), 719-726. https://doi.org/10.1016/j.ress.2006.03.004

[6] Bakouch, H. S., Al-Zahrani, B. M., Al-Shomrani, A. A., Marchi, V. A., Louzada, F., An extended Lindley distribution, Journal of the Korean Statistical Society, 41(1) (2012), 7585. https://doi.org/10.1016/j.jkss.2011.06.002

[7] Bekker, A., Roux, J., Mostert, P., A generalization of the compound Rayleigh distribution: using a Bayesian methods on cancer survival times, Communications in Statistics - Theory and Methods, 29 (2000), 1419-1433. https://doi.org/10.1080/03610920008832554

[8] Carrasco, J. M., Ortega, E. M., Cordeiro, G. M., A generalized modified Weibull distribution for lifetime modeling, Computational Statistics \& Data Analysis, 53(2) (2008), 450-462. http://dx.doi.org/10.1016/j.csda.2008.08.023

[9] Cheng, R. C. H., Amin, N. A. K., Maximum product of spacings estimation with application to the lognormal distribution, Mathematical Reports, (1979), 791.

[10] Fraser, D.A S., Probability and Statistics: Theory and Applications, North Scituate MA: Duxbury Press, 1976.

[11] Gomez-Deniz, E., Calderin-Ojeda, E., The discrete Lindley distribution: properties and applications, Journal of Statistical Computation and Simulation, 81(11) (2011), 1405-1416. https://doi.org/10.1080/00949655.2010.487825

[12] Ghitany, M.E., Al-Mutairi, D.K., Balakrishnan, N., Al-Enezi, L.J., Power Lindley distribution and associated inference, Computational Statistics and Data Analysis, 64 (2013), 20-33. https://doi.org/10.1016/j.csda.2013.02.026

[13] Karakaya, K., Tanıs, C. Estimating the parameters of Xgamma Weibull distribution, Adryaman University Journal of Science, 10(2) (2020), 557-571. https://doi.org/10.37094/adyujsci.781069

[14] Karakaya, K., Tanış, C. Different methods of estimation for the one parameter Akash distribution, Cumhuriyet Science Journal, 41(4) (2020), 944-950. https://doi.org/10.17776/csj.766011

[15] Korkmaz, M. C., Hamedani, G. G., An alternative distribution to Lindley and Power Lindley distributions with characterizations, different estimation methods and data applications, Mathematica Slovaca, 70(4) (2020), 953-978. https://doi.org/10.1515/ms-2017-0406

[16] Kuş, C., Akdoğan, Y., Asgharzadeh, A., Kınacı, İ., Karakaya, K., Binomial-discrete Lindley distribution, Communications Faculty of Sciences University of Ankara Series A1 Mathematics and Statistics, 68(1) (2018), 401-411.

[17] Lai, C. D., Xie, M., Murthy, D. N. P., A modified Weibull distribution, IEEE Transactions on Reliability, 52(1) (2003), 33-37.

[18] Lindley, D.V., Fiducial distributions and Bayes' theorem, Journal of the Royal Statistical Society Series B, 20 (1958), 102-107.

[19] Lucena, S. E., Silva, A. H. A., Cordeiro, G. M., The transmuted generalized gamma distribution: properties and application, Journal of Data Science, 13(1) (2015), 187-206. 
[20] Merovci, F., Sharma, V. K., The beta-Lindley distribution: properties and applications, Journal of Applied Mathematics, Article ID 198951, (2014), 1-10. https://doi.org/10.1155/2014/198951

[21] MirMostafaee, S. M. T. K., Mahdizadeh, M., Nadarajah, S., The beta Lindley distribution, Journal of Data Science, 13(3) (2015), 603-625.

[22] Nadarajah, S., Bakouch, H. S., Tahmasbi, R., A generalized Lindley distribution, Sankhya B, 73(2) (2011), 331-359. http://doi.org/10.1007/s13571-011-0025-9

[23] Nichols, M.D., Padgett, W. J., A bootstrap control chart for Weibull percentiles, Quality and Reliability Engineering International, 22 (2006), 141-151. http://doi.org/10.1002/qre.691

[24] Ozel, G., Alizadeh, M., Cakmakyapan, S., Hamedani, G. G., Ortega, E. M., Cancho, V. G., The odd log-logistic Lindley Poisson model for lifetime data, Communications in Statistics-Simulation and Computation, 46(8) (2017), 6513-6537. https://doi.org/10.1080/03610918.2016.1206931

[25] Ramesh, C., Gupta, S.N.U.A., Kirmani, On order relations between reliability measures, Stochastic Models, 3(1) (1987), 149-156.

[26] Salman S. M., Prayoto, S., Total time on test plot analysis for mechanical components of the RSG-GAS reactor, Atom Indones, 25(2) (1999), 155-161.

[27] Shaked, M., Shanthikumar, J. G., Stochastic Orders, Springer Verlag, New York, 2007.

[28] Stacy, E. W., A generalization of the gamma distribution, The Annals of Mathematical Statistics, 33(3) (1962), 1187-1192.

[29] Tanıs, C., On transmuted power function distribution: characterization, risk measures, and estimation, Journal of New Theory, 34 (2021), 72-81.

[30] Tanış, C., Karakaya, K., On estimating parameters of Lindley-geometric distribution, Eskişehir Technical University Journal of Science and Technology A-Applied Sciences and Engineering, 22(2) (2021), 160-167. https://doi.org/10.18038/estubtda.816836

[31] Warahena-Liyanage, G., Pararai, M., A generalized power Lindley distribution with applications, Asian Journal of Mathematics and Applications, (2014).

[32] Zakerzadeh, H., Dolati, A., Generalized Lindley distribution, Journal of Mathematical Extension, 3(2) (2009). 